\title{
Mitologia: Otro Nivel de Metalenguaje en Boquitas Pintadas
}

\author{
"PRIMERA ENTREGA
}

Era. . para mi la vida entera...

ALFREDO LE PERA

\begin{abstract}
NOTA APARECIDA EN EL NUMERO CORRESPONDIENTE A ABRIL 1947 DE LA REVISTA MENSUAL 'NUESTRA VECINIDAD', PUBLICADA EN LA LOCALIDAD DE CORONEL VALLEJOS, PROVINCIA DE BUENOS AIRES.
\end{abstract}

'FALLECIMIENTO LAMENTADO. La desaparición del señor Juan Carlos Etchepare, acaecida el 18 de abril último, a la temprana edad de veintinueve años, tras soportar las alternativas de una larga enfermedad, ha producido en esta población, de la que el extinto era querido hijo, general sentimiento de apesadumbrada sorpresa, no obstante conocer muchos allegados la seria afección que padecía.

Con este deceso desaparece de nuestro medio un elemento que, por las excelencias de su espíritu y carácter, destacóse como ponderable valor, poseedor de un cúmulo de atributos o dones--su simpatía--, lo cual distingue o diferencia a los seres poseedores de ese inestimable caudel, granjeándose la admiración de propios o extraños.

Los restos de Juan Carlos Etchepare fueron inhumados en la necrópolis local, lugar hasta donde fueron acompañados por numerosos y acongojado cortejo'."

Manuel Puig, Boquitas pintadas, Seix Barral (Barcelona, 1972), p. 9. 
El mito es metalenguaje; es un sistema de comunicación que consiste en un lenguaje, o sistema semiológico, de segundo orden dentro del cual se habla del de primer orden. ${ }^{1 *}$ Boquitas pintadas de Manuel Puig es una novela construida a base de mitos. Es posible reconocer en ella mitos dentro de mitos dentro de mitos, de la misma manera que se puede señalar, en otro nivel metalingǘstico, la presencia de textos incrustados que se abren a otros textos a la manera de una caja china. Sin embargo, hay dos mitos principales que claramente dominan la obra: el mito de los modelos sentimentales de la realidad pequeño-burguesa y el mito de la realidad pequeño-burguesa, pues según la definición de mito como metalenguaje, esta realidad es tan buena materia mítica como son los modelos de ella porque el mito no conoce. límites de sustancia, sólo de funciones: ${ }^{2}$ Para identificar y examinar la naturaleza de estos dos mitos, hemos elegido estudiarlos según son presentados en la primera página de la novela.

"Primera entrega" son las palabras que comienzan la primera página de Boquitas pintadas. ${ }^{3}$ Estas palabras forman un texto que, como suma de signos linguísticos, tiene un sentido completo e independiente: aquí comienza el primer episodio de una historia. Sin embargo, es evidente que este texto no se encuentra aquí sólo para presentar esta información; el texto tiene un sentido más allá del de primer orden y es este sentido de segundo orden lo que realmente determina la presencia de estas palabras en la página. La presencia de un sentido de segundo orden inmediatamente nos pone en el reino de mito, pues el mito es un tipo de habla que se define mucho más por su intención que por su sentido literal. ${ }^{4}$

${ }^{1}$ Roland Barthes, Mythologies, Editions du Seuil, coll. Points (Paris, 1957), p. 200 :

On le voit, il y a dans le mythe deux systèmes sémiologiques... un système linguistique. . .que j'appellerai langage-objet, parce qu'il est le langage dont le mythe se saisit pour construire son propre système; et le mythe lui-même, que j'appellerais méta-langage, parce qu'il est une seconde langue, dans laquelle on parle de la première.

* La definición es de Roland Barthes, Mythologies (Paris, 1957).

${ }^{2}$ Ibid., pp. 193-194:

On voit qu'il serait tout a fait illusoire de prétendre a une discrimination substantielle entre les objets mythiques: puisque le mythe est une parole, tout peut être mythe, qui est justiciable d'un discours. Le mythe ne se definit pas par l'objet de son message, mais par la façon dont il le profêre: il y a des limites formelles au mythe, il n'y en a pas de substantielles. Tout peut donc être mythe? Oui, je le crois. ....c'est l'histoire humaine qui fait passer le réel à l'état de parole, c'est elle et elle seule qui regle la vie et la mort du langage mythique. . .le mythe est une parole choisie par l'histoire: il ne saurait surgir de la "nature"des choses.

3 Manuel Puig, Boquitas pintadas, Seix Barral edición (Barcelona, 1972), p. 9.

4 Mythologies, p. 209:

Acerca de la frase "qui a ego nominar leo" en una gramática latina, Barthes observa:

Nous savons désormais que le mythe est une parole definie par son intention (je suis un exemple de grammaire) beaucoup plus que par sa lettre (je m'appelle lion). 
El sentido de segundo orden de este texto es que las palabras "Primera entrega" sirven como significantes-de un modelo sentimental de la realidad pequeño-burguesa, de un folletín, de una narración que se caracteriza por transiciones fluidas, personajes funcionales, continuidad de tiempo, de género y de narración, momentos de seudosuspenso que marchan hacia un desenlace final. Es decir, a la vez que se capta el sentido de "Primera entrega" en el primer orden, se revela la presencia de un sistema semiológico mayor. En este sistema semiológico mayor--o mito--hay un significante que se ha formado dentro del sistema previo, hay un concepto--modelo sentimental de la realidad pequeño-burguesa--y hay la presencia del concepto a través del significante, o sea hay significación. ${ }^{5}$

Aquí es importante notar que aunque estamos examinando la primera página de Boquitas pintadas, es una lectura de la primera página hecha posible sólo por una lectura previa de la novela entera. La intención, como notamos, es un elemento principal del concepto mítico y la intención se revela a través de la repetición. ${ }^{6}$ De manera que lo que permite la identificación del concepto mítico en esta primera página es la aparición repetida por toda la novela de textos incrustados, cuyo principal elemento común es su analogía con algún modelo sentimental de la realidad pequeño-burguesa. Esta lectura previa es necesaria porque el concepto mítico por definición no es "natural", sino que el mito es un sistema ideográfico puro en que las formas se motivan por el concepto que representan.?

El mismo proceso que se ha esquematizado en el caso de las palabras "Primera entrega" se repite con la aparición del segundo texto incrustado: "Era. . .para mí la

5

Ibid., p. 201.

De una fotografía en que un negro saluda la bandera francesa, Barthes percibe un mito:

... il y a un signifiant, formé lui-même, déjà, d'un systeme préalable (un soldat noir fait le salut militaire francais); il y a un signifié (c'est ici un mélange intentionnel de francité et de militarité); il y a enfin une présence du signifié a travers le signifiant.

Cuando aquí Barthes emplea la palabra "signifiè", la utiliza porque todavía en el ensayo no ha explicado la terminología distinta que pertenece a mitología. Más tarde, después de definir los términos míticos, él siempre emplea las palabras "signifiant", "concept", "signification" para hablar sobre este ejemplo y sobre el mito en general; emplea las palabras "signifiant", "signifié" y "signe" únicamente cuando se refiere a un sistema semiológico de primer orden. Por tal razón, cuando parafraseamos este trozo, tomamos en cuenta la totalidad de la presentación de Barthes y usamos las palabras "concepto" y "significación", que son las correctas para hablar de mito.

${ }^{6}$ Ibid., p. 205:

Cette répétition du concept a travers des formes différentes est précieuse pour le mythologue, elle permet de déchiffrer le mythe: c'est l'insistance d'une conduite qui livre son intention.

${ }^{7}$ Ibid., pp. 212-13:

D'abord, (la motivation) n'est pas "naturelle". . . Le mythe est un système idéographique pur, ot̀ les formes sont encore motivées par le concept qu'elles représentent. . . 
vida entera', Alfredo Le Pera" ${ }^{8}$ Como el anterior, este texto también tiene un sentido completo dentro de un sistema semiológico de primer orden. Sin embargo, la intención es otra vez más importante que el sentido literal del primer sistema. Aquí la presencia de este texto en la página no se debe solamente a una necesidad de delinear la relación entre el tanguero y la persona de quien canta; ni de relatar toda la historia de Cuesta abajo, ni tampoco de indicar que Alfredo Le Pera lo escribió para una película en que aparece Carlitos Gardel. El sentido de primer orden de este texto retrocede para que se revele una forma vacía, una forma que se llena por el mismo concepto mítico presente en el primer texto. ${ }^{9}$

El hecho de que un texto que señala un género literario y un texto que señala una canción y una película pueden significar lo mismo revela algunos aspectos importantes de la naturaleza del mito. Primero, señala que el mito no se restringe a los modos de la escritura. También puede hacerse de cualquier materia que ya se ha preparado para la comunicación. ${ }^{10}$ De manera que representaciones como fotografías, películas, periodismo, noticias, deportes, funciones, propaganda también pueden apoyar el habla mítico." El hecho de que "Primera entrega" y las palabras del tango Cuesta abajo pueden significar lo mismo subraya además el hecho de que el concepto mítico por definición puede tener un número enorme de posibles significantes. ${ }^{12}$ Dado estas posibilidades casi infinitas nos parece que para entender la selección de significantes que Puig ha hecho para esta novela hay que pensar en la relación entre sentido y forma dentro del significante mítico.

8

Puig, p. 9.

9 Mythologies, pp. 202-203:

Le signifiant du mythe se présente d'une façon ambigue: il est à la fois sens et forme, plein d'un côté, vide de l'autre. Comme sens, le signifiant postule déjà une lecture. . .le sens du mythe a une valeur propre. . .dans le sens, une signification est dejà construite, qui pourrait fort bien sè suffire à elle-même, si le mythe ne la saisissait et n'en faisait tout d'un coup une forme vide, parasite. . .En devenant forme, le sens éloigne sa contingence; il se vide, il s'appauvrit. . .

Y de nuevo empleando el ejemplo de la frase en una gramática latina, Barthes continúa :

Il faut reculer beaucoup l'histoire du lion pour faire place a l'exemple de grammaire (el concepto mítico).

10 Ibid.,p. 195:

. . la parole mythique est formée d'une matiere déjà travaillée en vue d'une

${ }^{11}$ Ibid., p. 194: communication appropriée. . .

Cette parole (mito) est un message. . .elle peut être formée d'écritures ou de représentations: le discours écrit, mais aussi la photographie, le cinéma, le reportage, le sport, les spectacles, la publicite, tout cela peut servir de support a la parole mythique.

12 Ibid., p. 205:

Un signifié peut avoir plusieurs signifiants: c'est notamente le cas du signifié linguistique et du signifié psychanalytique. C'est aussi le cas du concept mythique: il a à sa disposition une masse illimitée de signifiants: je puis trouver mille phrases latines qui me rendent présent l'accord de l'attribut, je puis trouver mille images qui me signifient l'impérialité française. 
Se ha indicado ya que en el mito el sentido de primer orden, es decir el sentido literal, retrocede para revelar una forma que se llena del concepto mítico. Esto es cierto, pero es también cierto que en este juego constante entre sentido y forma que define el significante mítico, el sentido nunca desaparece completamente. ${ }^{13}$ Este hecho es importante porque cualquier tango o radionovela o bolero o película sentimental en el nivel de forma podría haber significado el concepto: modelo sentimental de la realidad pequeño-burguesa. En el nivel de sentido, sin embargo, no todos podrían haberse relacionado con el sentido de los textos que significan la realidad pequeño-burguesa en la novela.

Es evidente que en la selección de significantes del nıodelo en Boquitas pintadas el autor se fijo tanto en el criterio de sentido como en el de forma, pres todos los significantes del modelo que aparecen muestran alguna analogía con el sentido de los textos que significan la realidad. La radionovela incrustada en la entrega decimotercera, por ejemplo, ofrece, como Severo Sarduy ha indicado en su excelente artículo sobre Boquitas pintadas, una analogía con el sentido de la realidad basada en inversiones. ${ }^{14}$ Lo mismo ocurre con las canciones que significan el modelo. La mayoría de los tangos, por ejemplo, tratan del regreso de un amor pasado y de la imposibilidad de recapturar el tiempo viejo. De esta manera revelan, en el nivel de sentido, una analogía con la situación de Nené, quien después de años de casada se atormenta por el fantasma de Juan Carlos. Además, casi todos los tangos pertenecen a la película sentimental, El día que me quieras, en que Gardel toma el papel de un tanguero, cuya joven esposa muere de tuberculosis. De nuevo, la analogía entre este sentido y el de los textos cuya significación de la realidad es clara, aunque de nuevo invertida en ciertos aspectos. Lo mismo ocurre con el bolero Nosotros, pues fue escrito por un hombre tuberculoso que, por su enfermedad, se veĺa forzado a abandonar a su mujer "en nombre de este amor y por tu bien". En fin, la importancia que la forma vacía del significante juega en la creación del mito no debe esconder la presencia, igualmente importante, del sentido. Es mayormente en el nivel de sentido que aparecen bastante semejanzas para justificar el diálogo entre textos y donde resaltan bastante diferencias para necesitar la identificación de dos conceptos distintos para llenar las formas.

"Empleamos las palabras "modelo" y "realidad" como abreviaciones para el mito cuyo concepto es modelo sentimental de la realidad pequeño-burguesa y para el mito cuyo concepto es la realidad pequefio-burguesa.

13 Ibid., p. 203:

Mais le point capital en tout ceci, c'est que la forme ne supprime pas le sens, elle ne fait que l'appauvrir, l'eloigner. . il faut sans cesse que la forme puisse reprendre racine dans le sens et s'y. alimenter en nature; . . .C'est ce jeu intéressant de cachecache entre le sens et la forme qui definit le mythe.

14 Severo Sarduy, "Notas a las Notas a las Notas. . .A Propósito de Manuel Puig", Revista Iberoamericana, vol. XXXVII, nums. 76-77 (julio-diciembre, 1971), p. 566. 
Hasta ahora se ha establecido la presencia en la primera página de Boquitas pintadas de un diálogo entre textos que participan como significantes en el mismo sistema mítico. La repetición de la misma significación en estos dos textos crea ciertas expectaciones acerca de la forma y del tono de los textos que seguirán. El tercer texto y el cuarto, sin embargo, rompen este esquema e interrumpen el diálogo armonioso entre los dos primeros textos.

El tercer texto es un titular que se señala a sí mismo y también a otro texto, el que sigue. La suma de signos linguísticos de este texto anuncia la aparición de una nota en la edición correspondiente a abril, 1947 de una revista provincial. El cuarto texto es esa nota, y su sentido de primer orden es anunciar y expresar pésame por la muerte de Juan Carlos Etchepare. En ambos textos, como ocurrió en los primeros dos textos, el sentido de primer orden retrocede para volverse forma y para permitir la ascensión de la intención que define el concepto mítico. Pero aquí termina la semejanza, pues estos dos textos se separan de los anteriores por ser textos periodísticos y por lo tanto participantes en otro sistema mítico. En el segundo orden, estos textos se vuelven significantes para el concepto mítico: la realidad pequeñoburquesa. Como era el caso en el primer concepto mítico que identificamos, también aquí es una lectura previa de la novela lo que ha permitido la identificación del concepto, pues aparecen consistentemente por la novela textos, cuyo principal denominador común es la ausencia de analogía con el concepto del primer mito y su analogía clara con la realidad cotidiana de los personajes dentro de la obra de ficción.

Cuando estos textos, cuya significación es la realidad pequeño-burquesa aparecen entre los textos, cuya significación es el modelo sentimental de aquella realidad, se produce un injerto de un tipo de discurso en otro. Este injerto es el elemento necesario para la parodia, la cual aquí definimos de acuerdo con el esquema desarrollado por Mikhail Bakhtine en L'oeuvre de François Rabelais et la culture populaire au Moyen Age et sous la Renaissance. ${ }^{15}$ Es decir, como Bakhtine, vemos una relación inevitable entre la parodia y la cultura popular o carnavalesca. La parodia se revela como un "segundo mundo" o "segunda vida" ambivalente en que se destruye y se renueva el "mundo oficial", el modelo, a la vez. ${ }^{16} \quad$ Es un segundo mundo en que la risa es alegre a la vez que es trágica y sarcástica. ${ }^{17}$ Es un segundo mundo en que hay, como Sarduy agrega, una "pluralidad de tonos, es decir habla del habla... [una mezcla de géneros, la intrusión, el injerto de un tipo de discurso en otro". ${ }^{18}$ La obra paródica se entiende, en fin, como un mundo que es a la vez una "apoteosis" y una "irrisión" del modelo de base..$^{19}$

15 Mikhail Bakhtine, L'oeuvre de François Rabelais et la culture populaire au Moyen Age et sous la Renaissance, Andrée Robel, trad. (Paris, 1970), pp. 1-67.

16 Ibid., pp. 19-20.

17 Ibid.

${ }_{19}^{18}$ Sarduy, pp. 556-57.

Ibid. 
La naturaleza--y no solamente la existencia--de la parodia en Boquitas pintadas se comienza a ver en la distancia êntre modelo y realidad que surge al examinar el contenido de estos textos míticos. Los dos textos que significan modelo sentimental de la realidad pequeño-burquesa se refieren implícitamente a un lenguaje especial. En el caso del primer texto, ese lenguaje es el lenguaje florido y artificialmente elegante del folletín; en el caso del segundo texto, el lenguaje es el dialecto popular del tango. En los dos casos, el lenguaje a que se refiere es sentimental. En cambio, el tercer texto se refiere a otro tipo de lenguaje, al lenguaje periodístico. El lenguaje que se encuentra en este texto es frío, informativo, práctico; reemplaza la subjetividad, poniendo en su lugar la objetividad, y muestra una ausencia total de sentimiento. El lenguaje del tercer texto es la inversión del señalado por los textos anteriores. El diálogo entre el tercer texto y los dos primeros textos, por lo tanto, no sólo introduce dos sistemas míticos distintos; también comienza a sugerir algo de la distancia que separa estos mitos.

Lo mismo se revela al examinar el cuarto texto en relación con los dos primeros. A diferencia del tercer texto con que comparte la significación realidad pequeñoburguesa, el cuarto texto sí contiene uno de los elementos de un modelo sentimental de la realidad. Tiene el lenguaje artificialmente elegante y serio que caracteriza el folletín. Sin embargo, la oposición entre modelo y realidad no es menos aquí que en el tercer texto; a pesar de la característica compartida con el modelo, hay también algo en este texto que prohibe que signifique el modelo. Este "algo" es la carencia total del sentimentalismo inherente al modelo. Por todo su lenguaje florido y elegante, el tono de este texto se semeja más al del tercer texto que al del modelo. Las palabras "lamentado", "temprana edad", "querido hijo", "sentimiento de apesadumbrada sorpresa", por ejemplo, tratan de ser significantes de gran y sincero dolor; las palabras "excelencias de su espíritu", "ponderable valor", "cúmulo de atributos o dones" tratan de ser significantes de profunda admiración. ${ }^{20}$ Sin embargo, lo que ocurre en este texto es que los significantes funcionan mal, pues nunca llegan exactamente al significado esperado o deseado. Hay un corto circuito en la cadena de acontecimientos lingiiísticos.

En el prólogo de Essais critiques, Roland Barthes ha notado el fenómeno de significantes que funcionan mal. Ha observado que muchas veces cuando uno trata de expresar un mensaje a través de las palabras convencionales que significan este mensaje, no se llega al significado. Por ejemplo, la palabra que debe expresar dolor por una muerte es "pésame". Sin embargo, si uno redujera el mensaje de dolor a esta sola palabra, no se llegaría al significado deseado, sino a su inversión. El mensaje parecería frío cuando en realidad lo que se quiere expresar es precisamente el calor y la sinceridad de los sentimientos. Lo que Barthes concluye de esta observación es que para expresar el verdadero mensaje, el calor de los sentimientos, es necesario corregir

Puig, p. 9. 
el mensaje, variarlo, inventar, producir algo más original y menos convencional. ${ }^{21}$

Esta explicación de Barthes sirve para delinear lo que ocurre en este cuarto texto. Lo que produce el corto circuito lingiústico en esta noticia fúnebre, lo que causa que los significantes de dolor y los de admiración y los de eleganica y seriedad nunce llegan al significado intentado es precisamente la sobreabundancia de frases convencionales, la falta de variación en el mensaje, la ausencia de invención. Este mismo tipo de corto circuito causado por la falta de invención se presenta vez tras vez en la novela (ejemplos claros son las cartas amorosas de Juan Carlos y las inscripciones colocadas en su tumba). Lo importante del mecanismo de estos cortos circuitos es que explica cómo el mito realidad pequeño-burguesa puede compartir algún elemento externo con el mito modelo sentimental y sin embargo carecer de o invertir totalmente la sustancia del modelo; de manera que la semejanza externa no disminuye la distancia sustancial entre los dos mitos.

En el nivel de los mitos en general también hay una especie de significantes que funcionan mal. Los dos primeros textos significan modelos sentimentales de la realidad pequeño-burguesa. Sin embargo, con la aparición de los textos siquientes lo que se presenta no es el concepto señalado, sino su ausencia o inversión. Es decir, la examinación del diálogo entre los cuatro textos que forman la primera página de Boquitas pintadas hace resaltar un hecho fundamental para la lectura de la novela entera: la novela contiene un sistema de significantes míticos que nunca llegan al concepto esperado, sino que se rompe por la presencia de otro; un sistema de significantes que funcionan mal hasta tal extremo que hay que aceptarlos como significantes falsos. Cada vez que la palabra "entrega" aparece, cada vez que se presenta un tango, un bolero, una referencia a una película sentimental o un folletín verdadero como la radionovela de la entrega decimotercera, lo que se espera es el concepto modelo sentimental de la realidad pequeño-burguesa y lo que se presenta no es el modelo sino el injerto de otro tipo de discurso, de textos cuya significación es

${ }^{21}$ Roland Barthes, Essais critiques, Editions du Seuil, coll. Tel Quel (Paris, 1964), pp. 11-12:

Un ami vient de perdre quelqu'un qu'il aime et je veux lui dire ma compassion. Je me mets alors a lui écrire spontanement une lettre. Cependant les mots que je trouve ne me satisfont pas: ce sont des"phrase": je fais des "phrases" avec le plus aimant de moi-même; je me dis alors que le message que je veux faire parvenir à cet ami, et qui est ma compassion même, pourrait en somme se reduire à un simple mot: Condoléances. Cependant la fin même de la communication s'y oppose, car ce serait là un message froid, et par conséquent inversé, puisque ce que je veuz communiquer, c'est la chaleur même de ma compassion. J'en conclus que pour redresser mon message (c'est-âd-dire en somme pour qu'il soit exact), il faut non seulement que je le varie, mais encore que cette variation soit originale et comme invente. 
realidad y cuyo contenido invierte el del modelo.

\section{Otros mitos más}

No se puede hablar de mitología en Boquitas pintadas sin señalar que en realidad los dos mitos que hemos examinado operan dentro del contexto de otro sistema mayor de mitos opuestos que es independiente del texto de la novela y que, sin embargo, determina en gran medida la lectura de ese texto. En uno de estos mitos, todos los modelos sentimentales de la realidad pequeño-burguesa--los tangos, los boleros, las películas, el folletin--se vuelven significantes para el concepto mítico: lo apasionado ideal. En el otro sistema mítico, el sentido de segundo orden de estos mismos modelos es completamente distinto y opuesto, pues en este segundo mito los modelos se vuelven significantes del concepto: lo cursi y lo ordinario. .

Hemos hablado ya del valor funcional del concepto mítico y de intención como un elemento principal en la definición de este concepto. La intención, naturalmente incluye los factores socio-históricos que son esenciales al mito. ${ }^{22}$ Es por el papel que la intención juega en el concepto que es posible que los mismos significantes lleguen a distintos conceptos.

\footnotetext{
* Obviamente este sistema comienza antes de la primera página, pues el título mismo, Boquitas Pintadas, es un significante false. Las palabras "boquitas pintadas" deben significar un modelo sentimental de la realidad pequeño-burguesa que, en el nivel de sentido se caracteriza por alegría y frivolidad. Sin embargo, dentro de la novela el título se identifica con Juan Carlos quien, siendo un don Juan tubérculo, cuyas boquitas pintadas son cuatro mujeres de la provincia, es sólo una sombra del tanguero en Rubias de New York. Más aun, el título de la novela llega a identificarse con la enfermedad de Juan Carlos, con los esputos de sangre de su tuberculosis y después, con la decadencia y la muerte de las boquitas azules, violáceas y negras de la segunda parte. Es decir, dentro de la novela nunca se llega al concepto significado por el título; al contrario, lo que se presenta es el concepto realidad que es una inversión patética del sentido del modelo.

El subtítulo también sirve como significante falso. Significa el modelo y sin embargo lo que sigue es una novela que se caracteriza no por la presencia de los elementos esperados, sino por su ausencia: ausencia de transiciones fluidas, ausencia de momentos de seudo-suspenso, ausencia de lenguaje elegante o ni siquiera sentimental, ausencia de personajes cuyos papeles son sólo funcionales, ausencia de narrador, ausencia de homogeneidad de tiempo y de género, en fin una ausencia total de lo que Sarduy llamaría los "lugares comunes" del modelo y la presencia de las inversiones de estos "lugares comunes" (Sarduy, p. 565).

Hay también otros significantes falsos, aunque de otra naturaleza, en la novela. Los textos que significan realidad en uno de los mitos principales, señalan en un sistema mítico menor la comunicación, pues todos son cartas, diarios, llamadas telefonicas, etc. Sin embargo, nunca se llega a ese concepto tampoco porque la comunicación verdadera en la novela siempre está limitada o por perspectiva o por hipocresía social. La tuberculosis de Juan Carlos, como ha notado Sarduy, es otro significante falso, pues en todavía otro sistema mítico menor podría significar un modelo romántico al cual la realidad de Juan Carlos nunca corresponde (Ibid., pp. 564-65).
}

22

Mythologies, pp. 204-05.

[El concepto mítico] est à la fois historique et intentionnel; il est le mobile qui fait proférer le mythe. L'exemplarité grammaticale [en referencia a la frase latina ya mencionada], l'imperialité française [en referencia a la foto del negro que saluda la bandera francesa] sont la pulsion mềme du mythe. Le concept rétablit une chaine 
Barthes ha examinado este fenómeno al notar cómo cambia el significado de un peinado "romano" en una película según si el público es norteamericano o francés. ${ }^{23}$. De la misma manera, es probable que alguien de la clase pequeño-burguesa que vivía en los años '30 o '40, como los personajes de la novela, acepte--por su experiencia cultural--estos modelos como significantes del mito de lo apasionado ideal. También es probable que alguien que se acerca a estos modelos unos treinta años después, siendo producto de una circunstancia cultural diferente, tenga la tendencia de verlos como sobras de la cultura burguesa que se han degradado, empobrecido, comercializado, que están fuera de moda; es decir, como significantes del mito cuyo concepto es lo cursi y lo ordinario. ${ }^{24}$

Aquí surge algo que en gran parte ha sido ignorado en la crítica de Boquitas pintadas : por el hecho de que la novela no sollo consiste de distintos sistemas míticos, sino que también presupone la existencia de un mito pre-textual, el papel del lector es de enorme, si no total importancia en la novela. La presencia de mito crea una situación verdaderamente borgesiana del lector como autor.

La lectura de la novela que se ha presentado en este trabajo subraya la distancia entre modelo y realidad y ve el juego entre estos dos mitos como el injerto de un tipo de discurso en otro, es decir de parodia. Esta lectura es posible solamente si el lector se acerca al texto aceptando de antemano o al menos por la duración de la novela, el mito en que los modelos de realidad son significantes de lo apasionado ideal. Es decir, esta lectura precisa que el lector acepte el mito pre-textual desde la misma perspectiva que lo verían los personajes novelescos.

Los mitos pre-textuales funcionan de tal manera qie si se acepta el otro posible mito en el cual los modelos significan lo cursi, la lectura de la novela entera se transforma. Lo clave de esta transformación es que al aceptar este segundo mito, las ideas de distancia y de ausencia en la novela cambian. En tal lectura, hay una distancia de antemano, que no existe en la primera lectura, entre el concepto que

de causes et d'effets, de mobiles et d'intentions. Contrairement à la formé, le concept est plein d'une situation. . le Temps, qui me fait nâitre à telle époque où la grammaire latine est enseignée; l'Histoire, qui me distingue par tout un. jeu de ségrégation sociale des enfants qui n'apprennent pas le latin; la tradition pédagogique qui fait choisir cet exemple dans Esope ou dans Phèdre; nues. propres habitudes linguistiques, qui voient dans l'accord de l'attribut un fait notanle, digne d'être illustré. . .le caractère fondamental du concept mythique, c'est d'être appropriê: l'exemplarité grammaticale concerne très précisément une classe d'eleves déterminée, l'imperialité française doit toucher tel groupe de lecteurs et non tel autre: le concept répond étroitement $a$ ane fonction, il se définit comme une tendance.

${ }^{23}$ Ibid., "Les Romains au cinéma", pp. 27-30.

${ }^{24}$ Ibid., p. 228:

Les normes petites-bourgeoises sont des résidus de la culture bourgeoise, ce sont des vérités bourgeoises dégradées, appauvries, commercialisées, leggerement archaisantes, ou si l'on préfère: demodées. 
acepta el lector y el que aceptan los personajes y que sirve para dar estructura a sus vidas. Precisamente por esta distancia inmediata, se reducen otras distancias que nosotros consideramos fundamentales. Por ejemplo, la naturaleza del diâlogo entre textos incrustados se transforma y se vuelve difícil hablar del injerto de un tipo de discurso en otro. Mientras que la idea del injerto antitético todavía funciona en un nivel mítico (es decir, se puede reconocer las diferencias externas entre un folletín verdadero y Boquitas pintadas), en el otro nivel mítico estas diferencias no tienen relevancia porque no representan nada más que el injerto de un significante de lo cursi en otro significante de lo cursi. Más aun, en tal lectura, sólo se puede hablar de apoteosis y de irrisión en un campo muy limitado. Es decir, en el nivel de los mitos intra-textuales existe irrisión en forma de la burla que el "folletín" Boquitas pintadas hace del folletín-modelo; pero de nuevo esta burla se restringe a lo externo, a la estructura narrativa del folletín. En tal lectura la sustancia y el tono del mito realidad no se burlan de los del mito modelo ni vice versa, sino que se confirman mútuamente porque en el nivel mítico pre-textual comparten el mismo concepto.

En fin, el lector se vuelve autor de Boquitas pintadas porque el mito pre-textual con que el lector se identifica condi iona la lectura de los mitos que aparecen dentro de la novela y por lo tanto, la de la novela entera. Si el lector no acepta el mito cuya significación es lo apasionado ideal de antemano, ni lo acepta al menos para la duración de la novela, es probable que se reduzca en gran medida en la novela el reino de la parodia según la hemos definido en este trabajo.

Nota final: mito como tecnica novelesca

El sistema de mitos antitéticos--sean pre-textuales o intratextuales--junto con el juego de significantes que al dialogar sólo subrayan la distancia entre sus conceptos, cumple una serie de funciones claves en Boquitas pintadas. Es, para comenzar, lo que permite que el autor sea significado por una ausencia, pues los textos míticos se comentan mútuamente y revelan a través de sus comentarios la perspectiva nada imparcial y muy presente del autor. El diálogo metalinguístico es también lo que desarrolla las ideas fundamentales de distancia y ausencia. De esta manera es lo que explica la relación entre los personajes novelescos, representados por los textosrealidad, y sus fantasías, representadas por los textos-modelo; es a la vez lo que explica la relación entre la novela Boquitas pintadas, en el último análisis un significante de la realidad, con su modelo. Este diálogo entre mitos es además la base de la parodia en la novela. Como la del Quijote, la parodia en Boquitas pintadas se encuentra en el juego entre apoteosis--la presencia de significantes del mito modelo de la realidad pequeño-burguesa--e irrisión--la inesperada ausencia de la sustancia de este mito, una ausencia que se llena por la presencia del mito realidad pequeñoburguesa; entre la analogía externa de los significantes míticos y la distancia sustancial entre sus conceptos; entre una serie de significantes que señalan un tipo de discurso y el injerto de otro tipo de discurso.

Todo esto suena muy "a la Sarduy"; y sin embargo, hay un punto de diferencia fundamental entre nuestra interpretación y la suya. Al hablar de mito en Boquitas pintadas, nosotros siempre hemos empleado la palabra segín la definición 
estructuralista de ella presentada por Roland Barthes. En cambio, Sarduy parece emplear la palabra "mito" en su artículo en otro sentido, pues parece sugerir una oposición entre realidad y mito que nosotros no reconocemos en Boquitas pintadas (por ejemplo: "A cada aproximación surge una disonancia, algo sobra, que, de la realidad, resiste a conformarse al andamiaje mítico..."). ${ }^{25}$ Para nosotros, la realidad en Boquitas pintadas, tanto como los modelos de esa realidad, es mito porque actúa en la novela como un sistema semiológico de segundo orden dentro del cual se habla del de primer orden, y, como ya señalamos, el mito se identifica por su función, no por su sustancia. Dentro del marco estructuralista que hemos empleado,no se puede hablar de una disonancia entre realidad y mito, sino de una disonancia entre dos mitos, uno cuyo concepto es modelo sentimental de la realidad pequeño-burguesa, y otro cuyo concepto es esa misma realidad.

Esta diferencia entre nuestra interpretación y la de Sarduy es importante porque revela que a pesar de los muchos puntos de acuerdo entre los dos análisis, Sarduy habla sobre un diálogo metalinguíístico, mientras que nosotros proponemos la existencia de un diálogo multi-metalinguístico. Es decir, al hablar de mito como un modo de significación en que un segundo sistema semiológico se refiere al primero, se señala implícitamente otro nivel de metalenguaje que Sarduy no considera en su artículo--un nivel, cuya presencia aumenta notablemente la complejidad de los juegos lingüisticos en Boquitas pintadas.

Yale University

Margery A. Safir

25 Sarduy, p.564 